\title{
Food pollutants and child health with special reference to the situation in the Aral Sea region in Kazakhstan By Rolf Zetterström
}

\begin{abstract}
Despite all progress in child health during this century, a number of hazards, which also may cause severe consequences in adult life, still remain. Thus, it has become obvious that environmental pollutants, which are found in various food products and drinking water, constitute a severe threat to human health and particularly for young children. Among such compounds, different organochlorins, such as pesticides for the control of parasites (DDTs, $\mathrm{HCHs}$ ), and products of industry and agriculture such as dioxins and dioxin-like compounds (PCBs) are much discussed, as well as organic mercury and heavy metals (lead and cadmium).

Consequences of acute intoxications with PCB have been documented in Japan following the ingestion of rice oil contaminated by PCBs. In Sweden birth weight has been found to be reduced and perinatal mortality rate higher than expected in regions with high consumption of fat fish and in that children who have been exposed to PCBs in utero have retarded cognitive development.

From the Aral Sea basin in Central Asia it has been reported that the population has been subjected to a long-term exposure to various organochlorins which in very large quantities have been distributed over the cotton fields. These compounds which are resistant in nature have entered the food chain leading to humans. As a consequence, organochlorins which have accumulated during fetal life continue to do so postnatally. The concentrations may be high in human milk. Children living in the Aral Sea region have poor health with high morbidity and mortality, high rate of chronic diseases and retarded development. They are subjected to many health hazards due to poverty and environmental pollution.

By proper epidemiological studies, it may be possible to obtain accurate information about the health risks of people who are exposed to environmental pollution from organochlorins, and also to device means of improving the situation.
\end{abstract}

\section{Introduction}

During the last 50 years, child health has improved in affluent countries to an extent, which has far exceeded the most optimistic expectations in the middle of this century. Due to better living conditions and efficient maternal, obstetric and neonatal care, perinatal mortality has declined to $1 / 5$ of the rate in 1950 , as shown in Figure 1 (1). In addition, a continuous improvement in nutrition and control of diarrhoea, respiratory infections and other infectious diseases have contributed to a rapid decline of infant and childhood mortality rates as exemplified by the secular trend in Sweden as is also

Rolf Zetterström, Prof emeritus, Department of Paediatrics, Karolinska Hospital, SE-171 76 Stock holm, Sweden.E-mail: mail@actapaediatrica.se

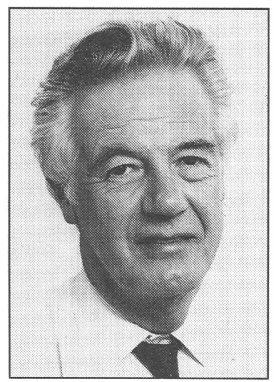

shown in Figure 1. The increasing prevalence of breast-feeding during the last 25 years, which is particularly obvious in the Scandinavian countries (Figure 2), is another favourable factor for the improvement of infant health.

However, despite all progress that has been made, a number of hazards to child health, which also may cause severe consequences in adult life, still remain. For instance, the increase in the incidence and prevalence of such immunopathological conditions, as atopic disease (2) and insulin dependent diabetes (3) in Sweden and several other European countries, causes great concern. New severe problems are also seen in the field of infectious diseases, such as the appearance of HIV

Figure 1. Rates of still-birth, first day, first week, first month and first year mortalities in Sweden 1945-1997 (1). Still-birth rate has not changed significantly during the last 15 years whereas infant mortality rate has gradually declined and is now approaching the still-birth rate.

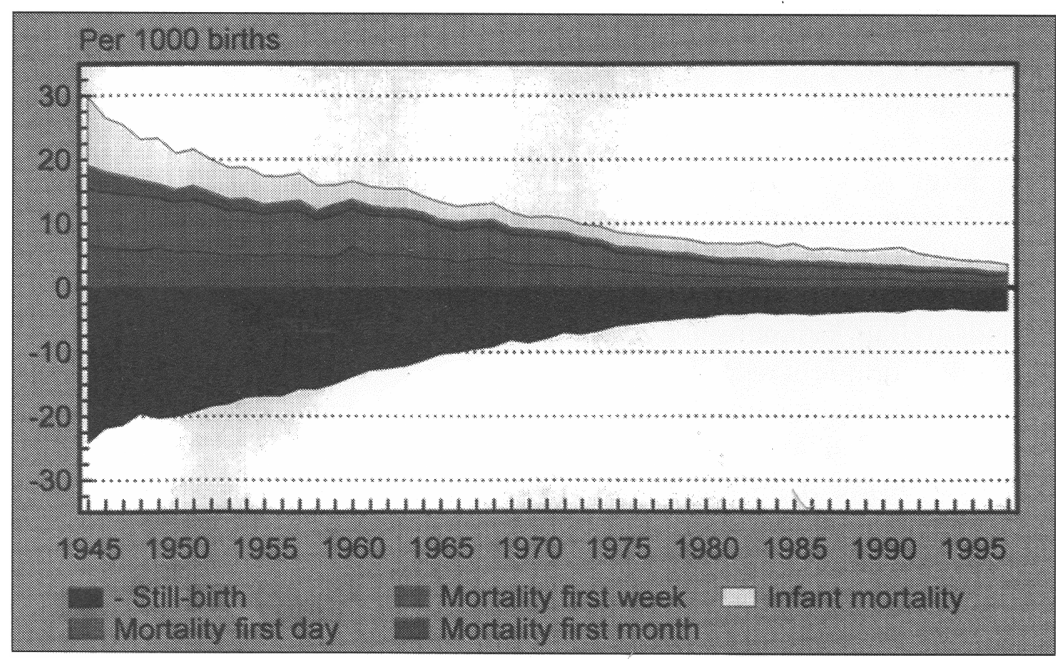


and other recently identified viral diseases. The dramatic increase of the number of pathogenic microorganisms which are resistant to antibiotics may not only be due to the widespread use of such drugs for treatment of various infections but also when used for the promotion of growth of animals that are used for meat production.

That environmental pollutants, which are found in various food products and drinking water, constitute a severe threat to human health and particularly for young children, has become obvious during the last decades, and has caused world-wide concern among professionals and lay people. Among much discussed toxic compounds are pesticides for the control of parasites and weeds, such as dichlorodisphenyl-trichloroethan compounds (DDTs), hexachloro-cyclohexane compounds (HCHs), organic mercury and products of industry and agriculture as dioxins and dioxin-like polychlorinated biphenyls (PCBs), heavy metals, arsenic or radionucleids may be mentioned.

\section{Ways of exposure to chlorinated contaminants}

Although such organochlorine contaminants as DDTs, various PCBs and dioxins are now banned in most countries, they may continue to enter the food chain and accumulate in humans due to their long half-life in nature. If present in the mother, foetuses may accumulate these lipophilic components following placental transfer and may thus occur at rather high levels in cord blood lipids $(4,5)$. In such instances, a further supply then continues postnatally if the infants are breast-fed as the milk lipids contain high concentrations of these compounds (6-8). After weaning, water and foodstuffs such as different crops and vegetables, fish and animal fat may contain further amounts of polychlorinated contaminants and of heavy metals.

\section{Clinical consequences of exposure to toxic components}

High morbidity and mortality have been reported following a number of acute or long-term exposures to various toxic agents. In the Minamata catastrophe in Japan in 1956 a large number of people of all ages who had eaten sea food, which was contaminated with organic mercury, were affected by a crippling chronic neurological disease. Another well-documented intoxication is the epidemic of $\mathrm{PCB}$ poisoning in Japan, and particularly in Kyushi in 1968 (Yusho disease) which affected people who had ingested rice oil which was contaminated with Kanechlor 400, a PCB mixture that had been used to minimise rice-oil odour during the manufac-
Figure 2. Prevalence of exclusive breast-feeding at 2, 4, and 6 months (a) and of breast-feeding with supplementary or complementary feeding at 2, 4, 6 and 9 months (b) in Sweden 1978-1997. (Data from Semper Foods 1998.)

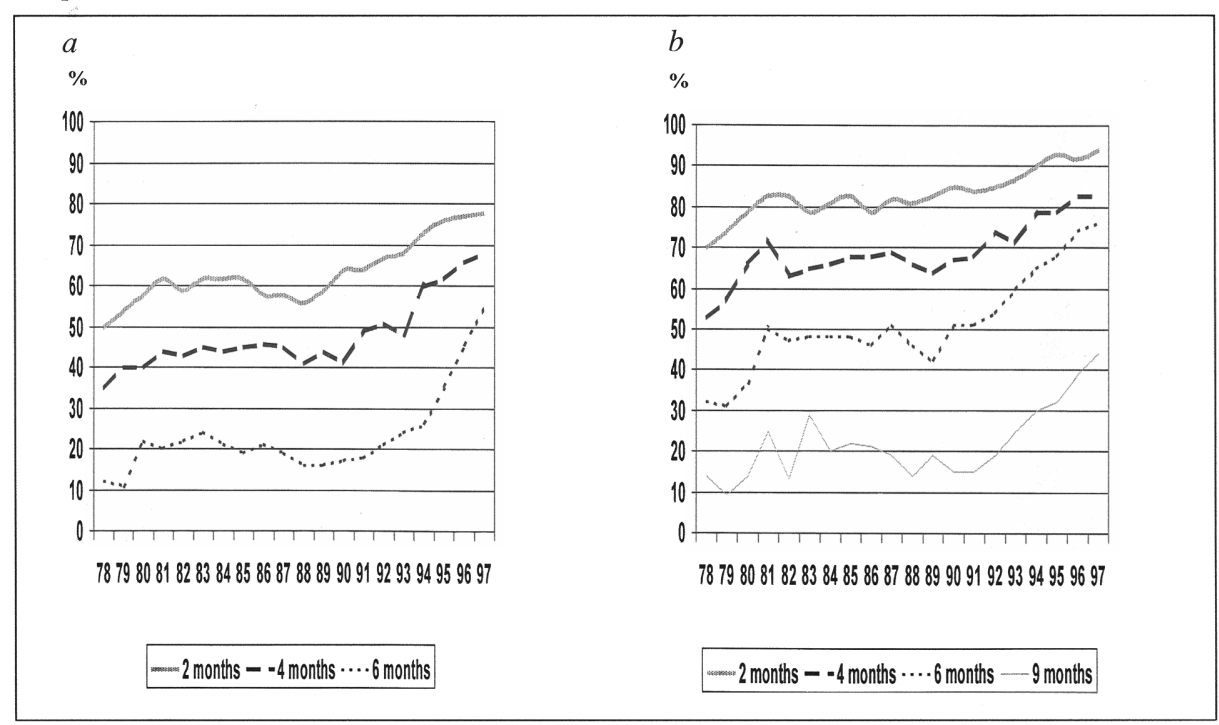

turing (9). The clinical and epidemiological characteristics in 325 patients with Yusho disease were thoroughly studied. Acneiform eruptions and skin pigmentations were the most obvious features but also such symptoms as general weakness and gastrointestinal disturbances were common (10). In congenital poisoning by polychlorinated biphenyls stillbirth rate is high and the Child health and food pollutionlyish or dark-brown pigmentations of skin, nails and gingiva as reported from Taiwan (11).

It has also been shown that intrauterine exposure to $\mathrm{PCBs}$ in concentrations, which are slightly higher than in the general population, causes deficient foetal and postnatal growth, retarded psychoneurological development and reduced cognitive ability at 11 years of age (12). Among people living at the coast of the Baltic Sea in the Swedish county of Ble- kinge and having a high intake of herring, perinatal mortality rate in 1974-1990 was $30-50 \%$ higher than in the rest of Sweden with a particular elevation of the stillbirth rate (1). It has also been reported that in the same population, the birthweight is decreased among infants born to women with a high dietary intake of fish contaminated with persistent organochlorine compounds (13). Furthermore, studies in the Netherlands have demonstrated that offspring of mothers who have been exposed to dioxins and PCBs during pregnancy have elevated plasma levels of thyroid-stimulating hormone (TSH) for at least 3 months after birth and that the plasma levels of free and total thyroxine are reduced during the second week after birth (14), findings, which document that intrauterine exposure to organochlorins may alter thyroid hormone status.

Figure 3. Map of the Central Asian republics. The region has a population of about 4 million people living in the three counties Karakalkpakstan, an autonomous region of Uzbekistan, Turkmenistan and Kazakhstan. The main tributary rivers to the Aral Sea are Syr Darya in Kazakhstan and Amu Darya in Uzbekistan. Both rivers are highly polluted from industries and agriculture, (particularly from cotton fields) along the whole reaches of the two rivers, which rise in Kirgizistan and Tadjikistan.

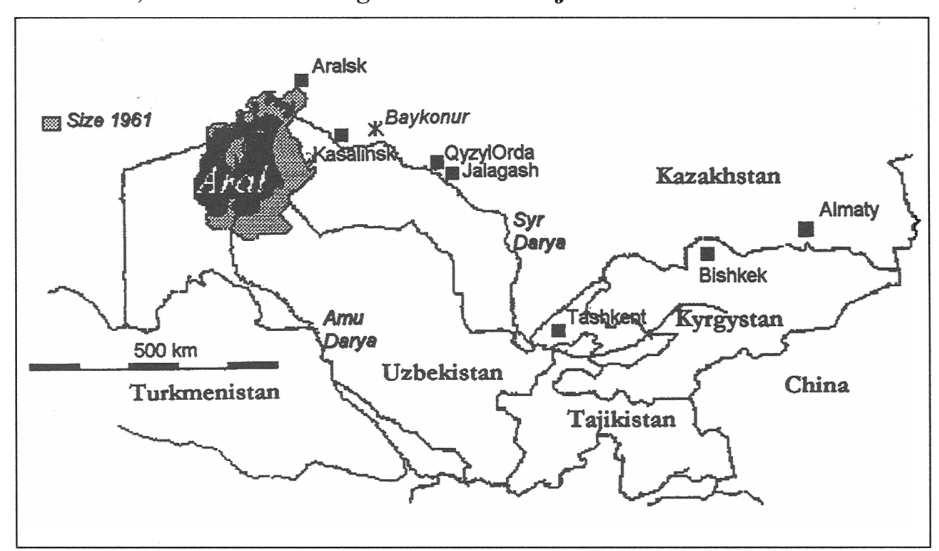


Figure 4. The drawings are demonstrating the decline of Aral Sea from 1960 until a predicted size for the year 2000 .

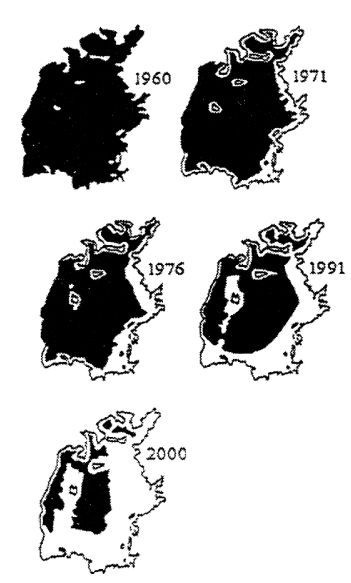

People living in the former Soviet Republics and particularly in the Aral Sea Basin have been subjected to severe health hazards from the exposure to large quantities of environmental pollutants (15) in addition to increasing impoverishment (16-17), and break-down of health services. Clinical and epidemiological studies in this region may thus give new and important information about the consequences of such exposures and about how to treat those who have been exposed. Furthermore, such studies may be of value to prevent that new groups of people become exposed.

\section{Ecological situation in the Aral Sea region}

In the Aral Sea region (Figure 3), economy was traditionally based on animal breeding, primitive agriculture, and fishing in the Aral Sea. When Soviet central planners in the 1950s decided to turn vast areas of

Figure 5. Selected gas chromatograms from the analysis of blood plasma lipids from children from Sweden (I) and the Aral Sea region in Kazakhstan (II) compared with a PCB standard (III). Numbers refer to different chloro-biphenyl congeners in Clophen A50. The sample in II is three times more diluted than in I. From (15).

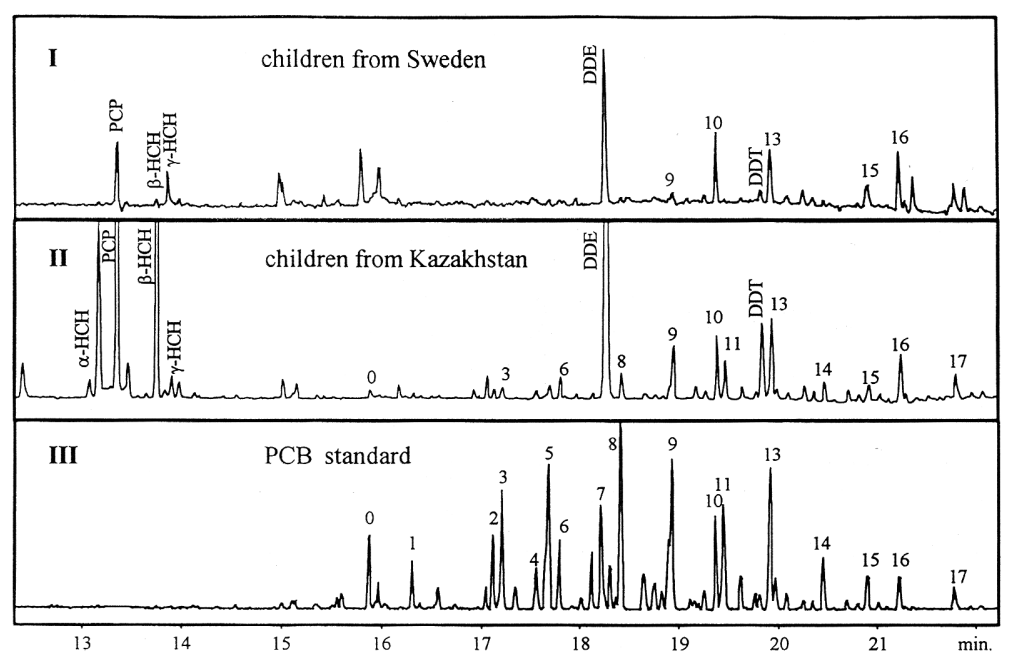

dry plains in Central Asia into cotton fields the situation was completely changed. In fact, a ruthless exploitation of the natural resources and a complete neglect of the needs of the local population and their traditions have caused a real ecocide (18). tion scheme to support the cotton fields in the former desert land, the water flow in the two rivers to the Aral Sea, i.e. Syr Darya and Amu Darya has been reduced to less than half, and during several years the water from these rivers has not even come close to the open sea. As most of the water from Amu Darya disappears in the former delta region, and Syr Darya dies in the patch plains outside Kazalinsk, which is more than 120 kilometres from its previous outlet, the Aral Sea has now lost nearly three-quarters of its water volume and its surface area has declined about $60 \%$ as shown in Figure 4.

Vast areas of former sea bottom have turned into sterile land with a high degree of salination and polluted by toxic chemicals derived from river sediments and other sources. The dense tamarisk vegetation which previously surrounded the Sea has completely vanished and the number of original mammals living around the Aral Sea has declined from 153 to 23 and the number of bird species from 310 to around 170 (19). When stormy winds sweep along these areas dense dust containing polluting agents are deposited over sport. In addition, polluted river water, which is used for irrigation, contaminates soil with toxic chemicals, which are then taken up by vegetables and other food products. As a result of an increasing salt concentration in the Aral Sea from 0.9 to $3.3 \%$, fish, which was one of the main The implementation of a massive irrigalarge distant regions by atmospheric tran- sources of protein for the population, have disappeared.

\section{Child health in the Aral Sea region in Kazakhstan}

According to official statistics, child health is deteriorating (19). Infant mortality rate which was around 25 per thousand in 1950 increased to $70-80$ per thousand in 1996. The rate of birth weight below 2500 $\mathrm{g}$ is about $10 \%$. Child growth is retarded and the growth spurt at 11 years of age is lacking in $53 \%$ of the girls. Compared to the situation 40 years ago, puberty is delayed in $33 \%$ of the girls and in $53 \%$ of the boys. Psychoneurological retardation is considered to be much more prevalent than expected.

School children from the Aral Sea region with clinical features considered to be caused by environmental pollution and thus diagnosed as "ecological disease" are since several years referred to Children's Rehabilitation Centre (URPAK) in Almaty for clinical work-up. These children exhibit multiple, medical problems such as acneiform eruptions and abnormal skin pigmentations, jaw malformations, enamel defects, gastritis and other gastrointestinal disorders, bronchiectasis, heart, liver or renal disease and suspected immunological deficiencies (18). Most of them are slightly retarded in their growth and the adolescents are moderately retarded in their sexual development compared to healthy Swedish children. The main cause of the poor health in these children is obviously not only due to exposure to toxic chemicals but also to poverty with crowding, poor sanitation and inadequate nutrition. Thus, diarrhoeal disease, tuberculosis and parasitic infections are common in the villages where the children live.

\section{Blood levels of environmental pollutants}

We have found that the levels of organochlorine compounds are much higher in the blood lipids of children living in the Aral Sea region than in Stockholm children as demonstrated on gaschromatograms (18). Thus, non of the $\mathrm{HCH}$-isomers, which are found in high concentrations in the children from the Aral Sea area occur in a detectable concentration in the Swedish reference groups (Figure 5 and Table 1). Children from the Aral Sea region had almost $1,000 \mathrm{ppb}$ of $\mathrm{HCH}$ on fat weight basis and the concentrations of PCB and DDT compounds were elevated by factors of 3 and 20, respectively (18) and in a study of a second group of children, extremely high individual values of $b$ $\mathrm{HCH}$ and DDT compounds of appro- 
ximately 5,000 ppb were found (18). In the same studies, it was found that the lead level in the hair of the Kazakhstani children was 30 times higher than the upper limit in hair from children in Hamburg in Germany, and in erythrocytes approximately 5 times higher than in children from Stockholm. The corresponding relation for cadmium in erythrocytes was 2.5 (18).

\section{Chlorinated contaminants,} growth and thyroid function

As it has been demonstrated that elevated levels of the dioxins and PCBs in newborn infants can alter their thyroid hormone status, we have studied the relation between the levels of some polychlorinated organic compounds in the blood lipids and growth and thyroid hormone status in twelve 7.5-15 years old school children from the Aral Sea region (20), all of whom had been hospitalised for skin manifestations or symptoms of gastritis, liver and kidney diseases (20). The plasma levels of TSH and total thyroxin were found to be within the Stockholm or Paris reference range. Although some of the children had extremely high levels of organochlorine pesticides, no relation to TSH or thyroxin levels was found. Body mass index (BMI) varied between -3.47 and +1.24 SDS and was below the mean in 10 of the 12 children but no relation was found between the height and the concentrations of organochlorine pesticides. The total DDT and PCB concentrations were inversely related to BMI SDS (Figure 6a,b). The IGF1 levels in blood where low, which might be a reflection of poor nutrition due to malabsorption from gastrointestinal damage by toxic compounds. In the children we studied and who obviously had been exposed both in utero and during early postnatal life to large amounts of PCBs and other chlorinated contaminants, no effect on thyroid hormone status was found. The explanation for the discrepancy between our findings and those reported from the Netherlands (14) may either be that the effect on thyroid hormone status disappears during development or that the pattern of contaminants is different in the Aral Sea region from that in the Netherlands.

\section{Discussion}

\section{Severe child health effects}

The main clinical features of the children who were admitted to the special hospital in Almaty from the Kazakh Aral Sea region, were retarded in growth and had delayed onset of puberty, anaemia, skin pigmentations with hyperkeratosis and dysplasia of mucous membranes of the oesophagus and stomach. In addition,

Table 1. Concentration of toxic chemicals in blood plasma ( $\mu \mathrm{g}$ per kg plasma-fat) in Kazakhstan compared to two reference groups in Sweden (Stockholm) .

\begin{tabular}{|c|c|c|c|c|c|}
\hline \multirow[t]{2}{*}{ Substance } & \multicolumn{2}{|c|}{ Sweden } & \multicolumn{2}{|c|}{ KZ, Aral Sea region } & \multirow[t]{2}{*}{ KZ, Almaty } \\
\hline & $\overline{\mathrm{SW}-1}$ & SW-2 & Village-1 & Village-2 & \\
\hline$\alpha-\mathrm{HCH}$ & nd & nd & 600 & 400 & 400 \\
\hline$\beta-\mathrm{HCH}$ & nd & nd & 200 & 400 & 200 \\
\hline$\gamma-\mathrm{HCH}$ & nd & nd & 70 & 90 & 70 \\
\hline$\sum-\mathrm{HCH}$ & - & - & 900 & 900 & 700 \\
\hline $\mathrm{HCB}$ & $<10$ & $<10$ & 40 & 20 & 10 \\
\hline DDE & 140 & 80 & 2,800 & 3,200 & 2,400 \\
\hline DDD & nd & nd & nd & nd & nd \\
\hline " $\Sigma$-DDT" & 150 & 90 & 3,300 & 3,800 & 3,100 \\
\hline
\end{tabular}

$\mathrm{HCH}=\mathrm{HexaChlorocycloHexane}(\boldsymbol{\gamma}-\mathrm{HCH}=$ Lindane $)$ $\mathrm{PCB}=$ Poly Chlorinaed Biphenyls
S-HCH $=$ Sum of $\alpha+\beta+\gamma$-isomers
"S-DDT" $=$ Sum of DDE + DDD + DDT

DDE = "Dichlorophenyl-DichloroEtylene"

DDD = "Dichloro-Diphenyl-Dichloroethane"

DDT = "Dichloro-Diphenyl-Trichloroethane"

nd $\quad=$ not detectable

many of them suffered from respiratory, liver, pancreatic and renal diseases and congenital heart disease occurred at a higher than expected rate. It is also known that early neonatal death caused by neonatal septicaemia is extremely common, and that respiratory and other lethal infections are very prevalent during infancy, indicating that immunological incompetence may be common.

As the cause of poor child health in the Aral Sea region obviously is multi-factorial, it is difficult to assess the role of exposure to toxic chemicals in relation to other predisposing factors such as deficiencies in macro or micro-nutrients, poor nutrition, frequent episodes of diarrhoea and other infectious diseases. However, it is quite obvious that many of the abnormal findings in the children from the Aral Sea region, such as hyperkeratosis, skeletal malformations and kidney disease have also been observed in Yushu disease and in seals, otters and minks from the Baltic Sea after having been exposed to PCBs and DDTs $(21,22)$. As prenatal exposure to polychlorinated biphenyls causes developmental toxic effects in experimental animals (23), and infants born to mothers, who have accidentally been poisoned by PCB contaminated rice oil or have eaten fish containing organochlorines, have intrauterine retardation of growth $(11,13)$ and a retarded cognitive and psychomotor development (12), it may be assumed that also children living in the Aral Sea region are affected by the same developmental defects.

Figure 6a. Relation between BMI Standard Deviation Score (BMI-SDS) and S-DDT in ng/g lipids in 12 children $(6 \mathrm{~m}$ and $6 \mathrm{f}$ ) of the age 7.5-15 years of age with multiple medical problems, including gastritis (in all of them), liver and kidney diseases and failure to thrive. Most to the children had a slight retardation of growth (-0.5 SDS) and the teenagers were moderately retarded in their sexual development compared to healthy Swedish children.

Figure 6b. Relation between BMI-SDS and S-PCB in ng/g lipids in the same children as in Figure 6 a.
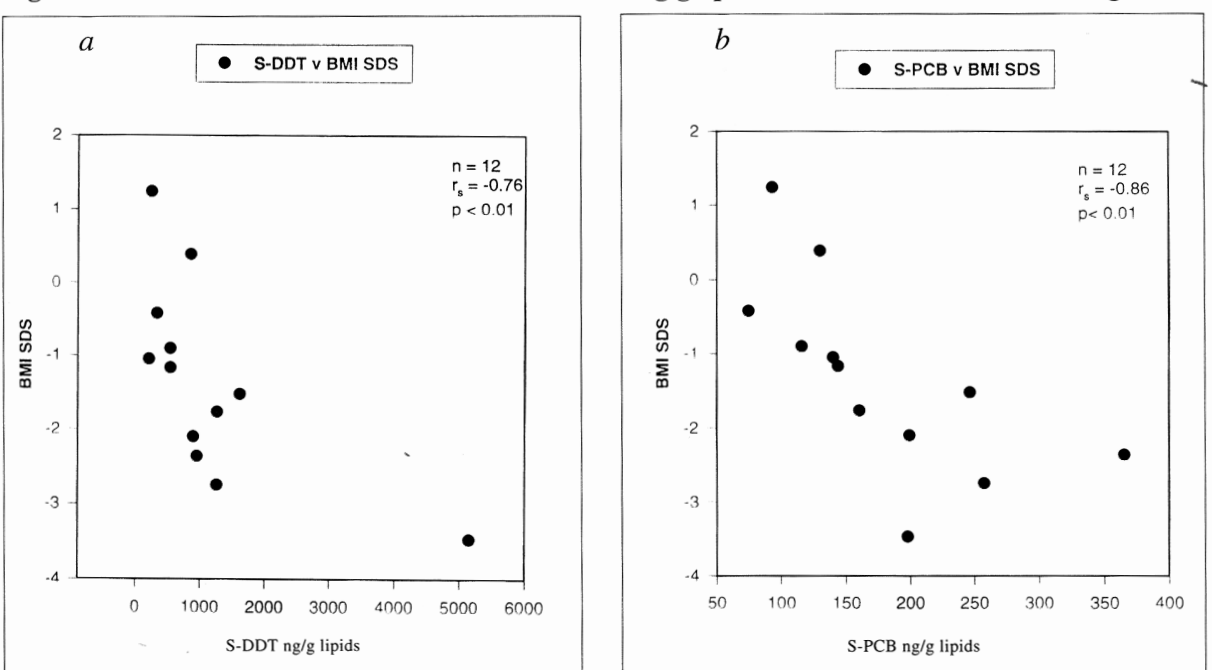
Table 2. Calcualted daily intake of some chlorinated contaminated by exclusivly breast-fed infants in Kazakhstan (ng/kg)*. Acceptable intake for total DDT is $20,000 \mathrm{ng} / \mathrm{kg}$ bw/day (WHO 1986).

\begin{tabular}{lcc}
\hline & Mean & Range \\
\hline Total DDT & 7,266 & $1,323-48,600$ \\
HCB & 328 & $25-1,848$ \\
$\beta-H C H$ & 7,014 & $1,806-13,616$ \\
Total PCBs & 1,424 & $627-5,662$
\end{tabular}

* Assuming a fat content of $3.5 \%$ and a daily intake of $120 \mathrm{ml} / \mathrm{kg}$. Petreas et al. 1996 (26).

\section{Prevention of exposure}

To prevent further exposure, the ways in which it happens must be considered. In Sweden, and among people living around Lake Michigan, the main exposure route for both PCB and other persistent organochlorine compounds seems to be the consumption of fatty fish, and from studies in the Netherlands, it has been found that fatty fish from the North Sea coast may have a high concentration of such organochlorine compounds as dioxins (24).

In Kazakhstan, and most probably also Uzbekistan and Turkmenistan large quantities of DDTs were used from the middle of the 1950 s to increase the yield of cotton. Due to the disastrous ecological effects of DDT, it was banned in 1972 (25). However, the very high peaks for unmetabolised DDTs as found in children from Kazakhstan indicate that such pesticides have been widely used until recently (19). However, after the prohibition of DDT in many countries, Toxaphene was introduced as a new and efficient pesticide. But after it had been used for about 10 years, it was found that it is carcinogenic and has mutagenic effects of what reason it was abandoned in Western countries in 1982. However, it remains unknown whether Toxaphene is still used in Central Asia.

Table 3. The concentrations of 2,3,7,8-TCDD in human milk by geographic area. (Mean $\pm S D$ ). From (26).

$\mathrm{pg} / \mathrm{g}$ fat

\begin{tabular}{lc}
\hline Agricultural district & ${ }^{1}$ \\
Almaty & $48 \pm 4$ \\
Atyrau & $8 \pm 2$ \\
Aralsk & $8 \pm 1$ \\
Chimkent & $4 \pm 0.3$ \\
QzylOrda & $8.5 \pm 1$ \\
& $5 \pm 0.4$
\end{tabular}

${ }^{1}$ Close to Kasalinsk and near Amyr Darya
Although it cannot be traced by blood analysis due to its short half-life in humans, its rather high stability in nature may cause contamination of food products like fish and vegetables. Some of the children we studied, had extremely high blood lipid levels of $\beta-\mathrm{HCH}$, an isomer which is a contaminant of $3-7 \%$ in crude $\mathrm{HCH}$, the product which also contains the isomer, i.e. Lindane, the active $\mathrm{HCH}$ pesticide, and which has been used from the 1950 s and until now without any reported effects. Due to a high biological stability of $\beta-\mathrm{HCH}$ compared to Lindane, it can be recovered in humans even if the exposure is low in relation to that of Lindane. However, whether $\beta-\mathrm{HCH}$ exhibits any toxic effect remains unknown. The fact that we did not observe any impact on thyroid status although the concentration of $\beta-\mathrm{HCH}$ was extremely high certainly does not exclude other toxic effects. Without question, toxic effects are caused by the high concentration of PCBs as found in children from the Aral Sea region and the origin of which may be their use for protection against weeds, and their addition to pesticides in order to delay vaporisation in a dry desert climate.

\section{High levels of dioxins \\ in breast milk}

In many instances the daily intake of chlorinated contaminants in exclusively breast-fed infants exceeds what is acceptable according to WHO, as shown by Petreas et al. (26) and demonstrated in Table 2. Most alarming for the health of infants in the Aral Sea basin is the finding that the extremely toxic compound 2,3,7,8-tetrachlorodibenz-para-dioxin (TCDD) has been found at a concentration of around $50 \mathrm{pg} \cdot \mathrm{g}^{-1}$ lipid in the milk of mothers from agricultural districts in Kazakhstan as shown in Table 3 (26) which is more than 10 times higher than in milk from Swedish mothers (27). It may also be mentioned that more than $80 \%$ of the total dioxin consists of this extremely toxic substance in human milk from Russian mothers, whereas it only accounts for about $10 \%$ in breast-milk from WestEuropean countries (28). This finding clearly indicates that TCDD in human milk in Kazakhstan emanates from impure formulations of the herbicide 2.4.5-trichlorophenoxyacetic acid, which was used as a defoliant in the Vietnam war in the 1960 s.

\section{Long-term effects}

To obtain further information about the long-term effect of exposure to organochlorines and other toxic compounds, many studies remain to be performed.
Thus, the relation between immuno-competence and blood lipid concentrations of organochlorines has to be studied (cf 29). Due to the fact that pollutants may induce mutations or predispose to the development of cancer, genotoxicity tests have to be performed in families, who have been exposed to PCBs and other organochlorines.

In areas where people have been exposed to toxic pollutants, like in the Aral Sea region, it is important to avoid further exposure. As a first measure, further spread of such pollutants should be banned. However, due to their persistence in nature, it is also of importance to study the degree of exposure to all people living in areas where it has been shown that the levels in breast-milk lipids from lactating mothers contains high concentrations of dioxins and other organochlorines (26, $30)$. It is quite obvious that those being heavily loaded with such compounds are at high health risk, and that methods aimed at eliminating them should be developed. In addition, a thorough study about the occurrence of organochlorine compounds in different sources of drinking water and food products, which are used in the Aral Sea region, has to be performed to avoid further exposure of people living in this region. The tolerance limit of infants who already in utero have been exposed should be studied so that a too heavy load will be avoided in breast-fed infants. On the other hand, the extreme importance of breastfeeding in the Aral Sea region, has to be considered in recommendations about infant feeding. The concentrations of various organochlorines in human milk from mothers from various regions and in the blood lipids from mother - infant pairs, thus have to be thoroughly studied.

Although the distance between the Aral Sea region and the Scandinavian countries is very large, it should be kept in mind that toxic compounds can be transported over large areas as demonstrated after the Chernobyl catastrophe in 1987. It is thus estimated that nowadays winds yearly transport 43 millions of tons of sediments containing salt, minerals and pesticides from an area of $30,000 \mathrm{~km}^{2}$ of former seabed, from the sinking Aral Sea to surrounding regions and as far as China and India (31) and there can expose people from water and local food products.

From our results of the high levels of organochlorines in blood lipids, it seems likely that the long standing exposure to these substances has been more severe in the Aral Sea region than in any other part of the world. In order to obtain accurate information about the health hazards of such exposures, accurate epidemiological and other scientific studies are needed. 
Only on the basis of such knowledge will it, in the future, be possible to avoid health risks in industrialised countries, and particularly in those countries now undergoing rapid industrialisation and agricultural development (32).

\section{Conclusions}

As the exposure to various toxic compounds, such as organochlorines and heavy metals that are persistent in nature, con-

\section{References}

1. Unit of Epidemiology. Swedish National Institute for Health and Welfare. Stockholm, Sweden. 1998.

2. Björkstén B. Risk factors in early childhood for the development of atopic disease. Allergy 1994; 49:400-7.

3. Dahlquist G. Epidemiological studies of childhood insulin-dependent diabetes. Acta Paediatr Scand 1991;80:583-9.

4. Schecter A, Päpke O, Ball M. Evidence for transplacental transfer of dioxins from mother to fetus: chlorinated dioxins and dibenzofuran levels in livers of stillborn infants. Chemosphere 1990;21:1017-22.

5. Lanting CI, Huisman M, Muskiet FAJ, van der Paauw CG, Essed CE, Boersma ER. Polychlorinated biphenyls in adipose tissue, liver, and brain from nine stillborns of varying
gestational ages. Pediatr Res $1998 ; 44: 2: 222-5$.

6. Norén K. Levels of organochlorine contaminants in human milk in relation to the dietary habits of mothers. Acta Paediatr Scand 1983;72:811-6.

7. Norén K. Changes in the levels of organochlorine pesticides, polychlorinated biphenyls, dibenzo-p-dioxins and dibenzofurans in human milk from Stockholm, 1972-1985. Chemosphere 1988;17:39-49.

8. Jensen AA. Chemical contaminants in human milk. Residue Rev 1983;89:1-28

9. Higuchi K. PCB Poisoning and pollution. In: Higuchi K, editor. Academic Press. Japan. Kodansha Ltd., 1976:3-7.

10. Kuratsune M, Yoshimura T, Matsuzaka J, Yamaguchi A. Epidemiolocigal study on Yusho, a poisoning caused by ingestion or rice oil contaminated with a commercial brand of polychlorinated biphenyls. Environ Health Perspect 1972;1:119-28.

11 Rogan WJ, Gladen BC, Hung K-L, Koong S-K, Shih L-Y, Taylor JS et al. Congenital poisoning by polychlorinated biphenyls and their contaminants in Taiwan. Science 1988;241: 334-6.

12. Jacobson JL, Jacobson SW. Intellectual impairment in children exposed to polychlorinated biphenyls in utero. N Engl J Med 1996; 335:783-9. stitute a severe threat to the health of humans and particularly to infants and children, it is extremely important that the relation between various qualitative and quantitative exposures and the clinical consequences are examined as ways of prevention of disastrous consequences can only be worked out on the basis of such knowledge. As the situation most likely is more severe in the Aral Sea basin than in any other part of the world, studies in this

13. Rylander L, Strömberg U, Hagmar L. Decreased birthweight among infants born to women with a high dietary intake of fish contaminated with persistent organochlorine compounds. Scand $\mathbf{J}$ Work Environm Health 1995;21:368-75.

14. Koopman-Esseboom C, Morse DC, WeisglasKuperus N, Lutkeschipholt IJ, van der Paauw $\mathrm{CG}$, Tuinstra LGM et al. Effects of dioxins and polychlorinated biphenyls on thyroid hormone status of pregnant women and their infants. Pediatr Res 1994;36:468-73.

15. Galiulin RVZ, Bashkin VIV Predecessors of dioxins - DDT and PCBs in irrigated agrolandscapes of Russia and Uzbekistan. Transport and fate. Environmental levels. Toxaphenes, $\mathrm{PCBs}$ and other Non-Dioxins. Dioxin 96. Organohalogen Compounds 28. 1996;459-62.

16. Feshbach M, Friendly Jr A. Ecocide in the USSR. Washington DC: Georgetown University Press, 1992:1-376.

17. Feshbach M. Ecological disaster cleaning up the hidden legacy of the Soviet regime. New York: The Twentieth Century Fund Press, 1995:1-157.

18. Jensen S, Mazhitova Z, Zetterström R. Environmental pollution and child health in the Aral Sea region in Kazakhstan. Science Tot Environm 1997;206:187-93.

19. Nikanova S, Nazarova T. Yesterday and now Aral-problems and perspectives of Aral's crisis. In: Nikanova S, Nazarova T, editors. UNDP, The World Bank 1997:1-126.

20. Mazhitova Z, Jensen S, Zetterström R. Chlorinated contminants, growth and thyroid function in schoolchildren from the Aral Sea region in Kazakhstan. Acta Paediatr 1998;87:991-6.

21. Jubb KFV, Kennedy PC. (eds.) Pathology of domestic animals. 2 ed, Academic Press, New York, 1970;1:518-521.

22. Blomkvist G, Roos A, Jensen S, Bignert A, Olsson M. Concentrations of SDDT and PCB in seals from Swedish and Scottish waters. Ambio,1992;21;539-45.

23. Brouwer A, Ahlborg UG, Van den Berg M, Birnbaum LS, Boersma RE, Bosveld ATC et al. Functional aspects of developmental toxicity of region are of particular importance.

By the results of cross-sectional scientific, chemical, ecological and investigations, it will not only be possible to improve the conditions for the people living in the Aral Sea region but also to learn more about what guidelines need to be worked out so that catastrophes similar to those in the Central Asian countries will be avoided in other countries undergoing rapid industrialisation.

polyhalogenated aromatic hydrocarbons in experimental animals and human infants. Eur $J$ Pharmacol: Environ Toxicol \& Pharmacol 1995;293:1-40.

24. Sauer PJJ, Huisman M, Koopman-Esseboom C, Morse DC, Smits-Van Prooije AE, Van den Berg $\mathrm{KJ}$ et al. Effects of polychlorinated biphenyls and dioxins on growth and development. Human Exp Toxicol 1994;13:900-6.

25. Ueda K. Toxicological aspects I: The toxicity of PCBs: In: PCB poisoning and pollution. Tokyo: Kodanska Ltd and New York: Academic Press, 1976;25-40.

26. Petreas M, Hooper K, She J et al. Analysis of human breast milk to assess exposure to chlorinated contaminants in Kazakhstan. Human exposure. Human health risk assessment. Dioxin 96. Organohalogen compounds. 1996;30;20-3.

27. Norén K. Lunden Å. Petterson E, Bergman Å Methylsulfonyl metabolites of PCBs and DDEs in human milk in Sweden, 1972-1992. Environ Health Perspect 1996;104:766-72.

28 Higuchi K (Ed.) PCB Poisoning and Pollution. Tokyo: Kodanska Ltd. and New York: Academic Press 1976.

29. Svensson BG, Hallberg T, Nilsson A, Schutz A, Hagmar L. Parameters of immunological competence in subjects with high consumption of fish contaminated with persistent organochlorine compounds. Int Arch Occup. Environ Health 1994:65;351-8.

30. Lutter C, Iyengar V, Barnes R, Chuvakova T, Sharmanov T. Breast-milk contamination in Kazakhstan: Implications for infant feeding. Human exposure. Human health risk assessment. Dioxin 96. Organohalogen compounds 1996;30:24-30.

31. McConnell LL, Kucklick JR, Bidleman TF, Ivanov GP, Chernyak SM. Air-water-gas exchange of organochlorine compounds in Lake Baijkal Environ Sci Technol 1996;30;2975-83.

32. Lindahl-Kiessling K, Landberg H. Population economic development and the environment. The making of our common future. Oxford: Oxford University Press, Oxford V-VIII 1994:1-284. 